\title{
Plant Growth Promoting Rhizobacteria (PGPR): Current and Future Prospects for Development of Sustainable Agriculture
}

Govind Gupta, Shailendra Singh Parihar, Narendra Kumar Ahirwar, Sunil Kumar Snehi and Vinod Singh*

Department of Microbiology, Barkatullah University, Bhopal, India

\begin{abstract}
Soil is dynamic living matrix and it is not only a critical resource in agricultural and food security but it is also towards maintenance of all life process. Pathogenic microorganisms affecting plant health are a major and chronic threat to sustainable agriculture and ecosystem stability worldwide. The chemical fertilizers used in the agriculture to increase yields, kill pathogens, pests, and weeds, have a big harmful impact on the ecosystem. Because of current public concerns about the side effects of agrochemicals, there is an increasing interest in improving the understanding of cooperative activities among plants and rhizosphere microbial populations. So, there is an urgent need of biological agents is accepted worldwide. The use of plant growth promoting Rhizobacteria (PGPR) is a better alternative to solve this problem. They play an important role to increase in soil fertility, plant growth promotion, and suppression of phytopathogens for development of ecofriendly sustainable agriculture. This review provides environment friendly approach to increase crop production and health, development of sustainable agriculture and commercialization by using of plant growth promoting rhizobacteria with global applicability.
\end{abstract}

Keywords: Plant growth promoting rhizobacteria; Bio-fertilizers; Biocontrol; Sustainable agriculture

\section{Introduction}

In modern cultivation process indiscriminate use of fertilizers, particularly the nitrogenous and phosphorus, has led to substantial pollution of soil, air and water. Excessive use of these chemicals exerts deleterious effects on soil microorganism, affects the fertility status of soil and also pollutes environment [1]. The application of these fertilizers on a long term basis often leads to reduction in $\mathrm{pH}$ and exchangeable bases thus making them unavailable to crops and the productivity of crop declines. To obviate this problem and obtain higher plant yields, farmers have become increasingly dependent on chemical sources of nitrogen and phosphorus. Besides being costly, the production of chemical fertilizers depletes nonrenewable resources, the oil and natural gas used to produce these fertilizers, and poses human and environmental hazards [2].

Over the last few decades, the agriculture policy in India has undergone a major change through diversification and emphasis on sustainable production system. Rhizosphere researches have been throwing up surprise and interesting ideas for research ever since the pleasant environment of microorganisms around plant root called rhizosphere. The term rhizosphere was introduced for the first time by Hiltner [3]. The major influences that the rhizosphere microorganisms have on plants today become important tool to guard the health of plants in ecofriendly manner [4]. These microorganisms can effect plant growth often referred to as a plant growth promotory rhizobacteria [5]. They are involved in various biotic activities of the soil ecosystem to make it dynamic for nutrient turn over and sustainable for crop production [6]. In recent years considerable attention has been paid to PGPR to replace agrochemicals (fertilizers and pesticides) for the plant growth promotion by a variety of mechanisms that involve soil structure formation, decomposition of organic matter, recycling of essential elements, solubilization of mineral nutrients, producing numerous plant growth regulators, degrading organic pollutants, stimulation of root growth, crucial for soil fertility, biocontrol of soil and seed borne plant pathogens and in promoting changes in vegetation [7]. An understanding of plant growth promoting rhizobacteria and their interactions with biotic and abiotic factors is indispensable in bioremediation techniques [8] energy generation processes and in biotechnological industries such as pharmaceuticals, food, chemical, and mining. Furthermore plant growth promoting rhizobacteria can reduce chemical fertilizers application and economically, environmentally beneficial for lower production cost as well as recognize the best soil and crop management practices to achieve more sustainable agriculture as well as fertility of soil [9].

\section{Plant Growth Promoting Rhizobacterial Forms}

Plant growth promoting rhizobacteria can be classified into extracellular plant growth promoting rhizobacteria (ePGPR) and intracellular plant growth promoting rhizobacteria (iPGPR) [10]. The ePGPRs may exist in the rhizosphere, on the rhizoplane or in the spaces between the cells of root cortex while iPGPRs locates generally inside the specialized nodular structures of root cells. The bacterial genera such as Agrobacterium, Arthrobacter, Azotobacter, Azospirillum, Bacillus, Burkholderia, Caulobacter, Chromobacterium, Erwinia, Flavobacterium, Micrococcous, Pseudomonas and Serratia belongs to ePGPR [11]. The iPGPR belongs to the family of Rhizobiaceae includes Allorhizobium, Bradyrhizobium, Mesorhizobium and Rhizobium, endophytes and Frankia species both of which can symbiotically fix atmospheric nitrogen with the higher plants [12].

\section{Plant Growth Promotion: Mechanism of Action}

Plant growth promotion by plant growth promoting rhizobacteria is a well-known phenomenon and this growth enhancement is due

*Corresponding author: Vinod Singh, Department of Microbiology, Barkatullah University, Bhopal, India, Tel: 0755251 7100; E-mail: vinodsingh63@yahoo.co.in

Received January 24, 2015; Accepted March 17, 2015; Published March 24, 2015

Citation: Gupta G, Parihar SS, Ahirwar NK, Snehi SK, Singh V (2015) Plant Growth Promoting Rhizobacteria (PGPR): Current and Future Prospects for Development of Sustainable Agriculture. J Microb Biochem Technol 7: 096-102. doi:10.4172/1948-5948.1000188

Copyright: $\odot 2015$ Gupta G, et al. This is an open-access article distributed under the terms of the Creative Commons Attribution License, which permits unrestricted use, distribution, and reproduction in any medium, provided the original author and source are credited 
to certain traits of rhizobacteria. There are a number of mechanisms used by PGPR for enhancing plant growth and development in diverse environmental conditions (Figure 1). According to Kloepper and Schroth [13] plant growth promoting rhizobacteria mediated plant growth promotion occurs by the alteration of the whole microbial community in rhizosphere niche through the production of various substances. Generally, plant growth promoting rhizobacteria promote plant growth directly (Figure 1) by either often due to their ability for nutrient supply (nitrogen, phosphorus, potassium and essential minerals) or modulating plant hormone levels, or indirectly by decreasing the inhibitory effects of various pathogens on plant growth and development in the forms of biocontrol agents, root colonizers, and environmental protectors [13].

\section{Direct mechanisms}

Plant growth promoting rhizobacteria having direct mechanisms that facilitate nutrient uptake or increase nutrient availability by nitrogen fixation, solubilization of mineral nutrients, mineralize organic compounds and production of phytohormones [14,15].

Nitrogen fixation: Nitrogen is an essential element for all forms of life and it is the most vital nutrient for plant growth and productivity. Although the nitrogen presents $78 \%$ of the atmosphere, it remains unavailable to the plants. Regrettably no plant species is capable for fixing atmospheric dinitrogen into ammonia and expend it directly for its growth. Thus the atmospheric nitrogen is converted into plantutilizable forms by biological nitrogen fixation (BNF) which changes nitrogen to ammonia by nitrogen fixing microorganisms using a complex enzyme system known as nitrogenase [16].

Plant growth promoting rhizobacteria have the ability to fix atmospheric nitrogen and provide it to plants by two mechanisms: symbiotic and non-symbiotic. Symbiotic nitrogen fixation is a mutualistic relationship between a microbe and the plant. The microbe first enters the root and later on form nodules in which nitrogen fixation occurs. Rhizobia are a vast group of rhizobacteria that have the ability to lay symbiotic interactions by the colonization and formation of root nodules with leguminous plants, where nitrogen is fixed to ammonia and make it available for the plant [11]. The plant growth promoting rhizobacteria widely presented as symbionts are Rhizobium, Bradyrhizobium, Sinorhizobium, and Mesorhizobium with leguminous plants, Frankia with non-leguminous trees and shrubs [17].

On the other hand, non-symbiotic nitrogen fixation is carried out by free living diazotrophs and this can stimulate non-legume plants growth such as radish and rice. Non-symbiotic Nitrogen fixing rhizospheric bacteria belonging to genera including Azoarcus, Azotobacter, Acetobacter, Azospirillum, Burkholderia, Diazotrophicus, Enterobacter, Gluconacetobacter, Pseudomonas and cyanobacteria (Anabaena, Nostoc) [12,18]. The genes for nitrogen fixation, called nif genes are found in both symbiotic and free living systems [19]. Nitrogenase (nif) genes include structural genes, involved in activation of the $\mathrm{Fe}$ protein, iron molybdenum cofactor biosynthesis, electron donation, and regulatory genes required for the synthesis and function of the enzyme. Inoculation by biological nitrogen fixing plant growth promoting rhizobacteria on crop provide an integrated approach for disease management, growth promotion activity, maintain the nitogen level in agricultural soil.

Phosphate solubilization: Phosphorus is the most important key element in the nutrition of plants, next to nitrogen $(\mathrm{N})$. It plays an important role in virtually all major metabolic processes in plant including photosynthesis, energy transfer, signal transduction, macromolecular biosynthesis and respiration [20]. It is abundantly available in soils in both organic and inorganic forms. Plants are unable to utilized phosphate because $95-99 \%$ phosphate present in the insoluble, immobilized, and precipitated form [21]. Plants absorb phosphate only in two soluble forms, the monobasic $\left(\mathrm{H}_{2} \mathrm{PO}_{4}\right)$ and the diabasic $\left(\mathrm{HPO}_{4}^{2-}\right)$ ions [12].

Plant growth promoting rhizobacteria present in the soil employ different strategies to make use of unavailable forms of phosphorus and in turn also help in making phosphorus available for plants to absorb. The main phosphate solubilization mechanisms employed by plant growth promoting rhizobacteria include: (1) release of complexing or mineral dissolving compounds e.g. organic acid anions, protons,

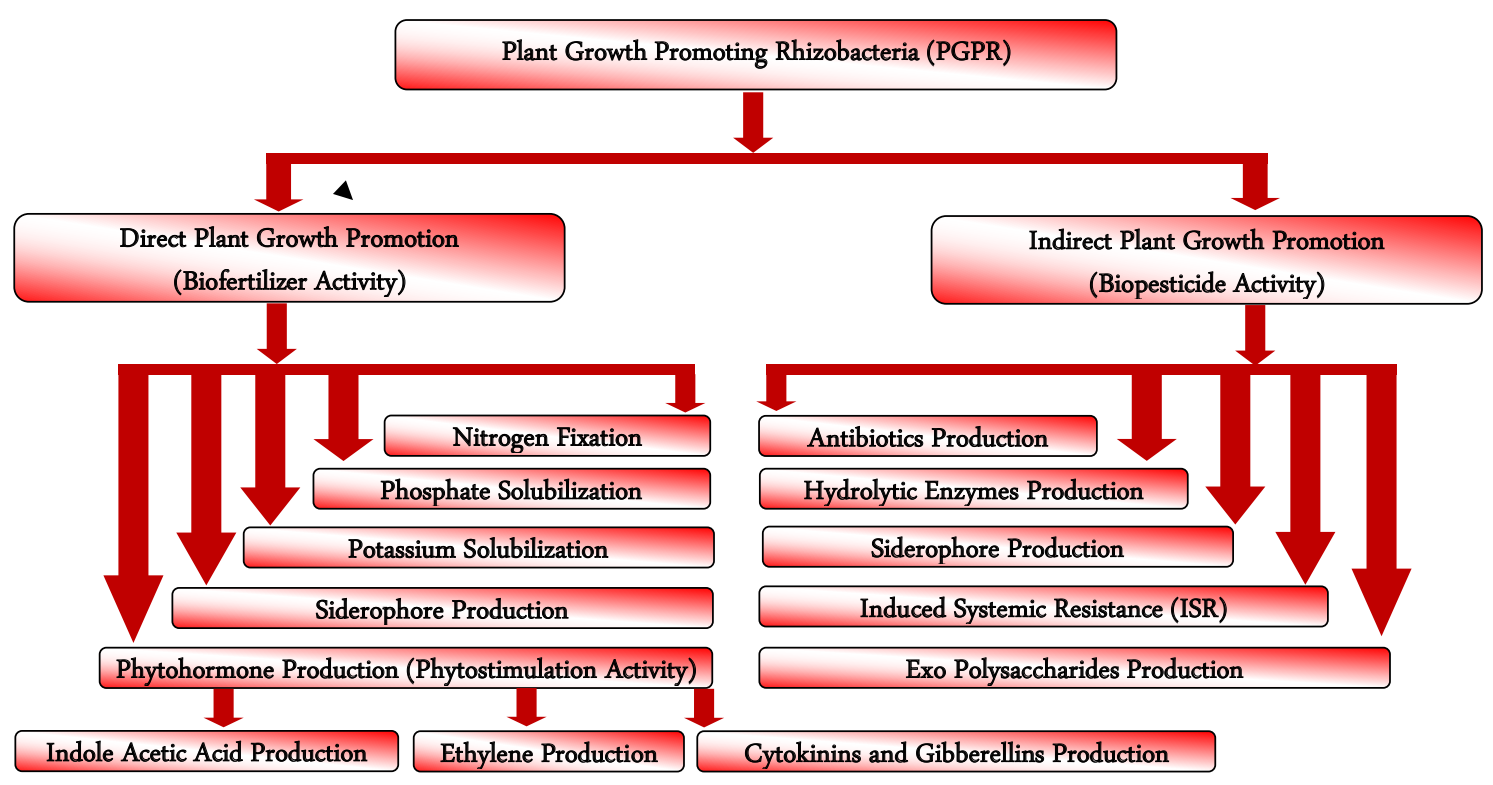

Figure 1: Shematicdigram showing plant growth promoting bacteria affect plant growth directly and indirectly. 
hydroxyl ions, $\mathrm{CO}_{2}$, (2) liberation of extracellular enzymes (biochemical phosphate mineralization) and (3) the release of phosphate during substrate degradation (biological phosphate mineralization) [22].

Phosphate solubilizing PGPR included in the genera Arthrobacter, Bacillus, Beijerinckia, Burkholderia, Enterobacter, Erwinia, Flavobacterium, Microbacterium Pseudomonas, Rhizobium, Rhodococcus, and Serratia have attracted the attention of agriculturists as soil inoculums to improve plant growth and yield [12]. However, the beneficial effects of the inoculation with phosphate solubilizing bacteria used alone or in combination with other rhizospheric microbes have been also reported [23].

Potassium solubilization: Potassium $(\mathrm{K})$ is the third major essential macronutrient for plant growth. The concentrations of soluble potassium in the soil are usually very low and more than $90 \%$ of potassium in the soil exists in the form of insoluble rocks and silicate minerals [24]. Moreover, due to imbalanced fertilizer application, potassium deficiency is becoming one of the major constraints in crop production. Without adequate potassium, the plants will have poorly developed roots, grow slowly, produce small seeds and have lower yields. This emphasized the search to find an alternative indigenous source of potassium for plant uptake and to maintain potassium status in soils for sustaining crop production [25].

Plant growth promoting rhizobacteria are able to solubilize potassium rock through production and secretion of organic acids [26]. Potassium solubilizing plant growth promoting rhizobacteria such as Acidothiobacillus ferrooxidans, Bacillus edaphicus, Bacillus mucilaginosus, Burkholderia, Paenibacillus sp. and Pseudomonas has been reported to release potassium in accessible form from potassiumbearing minerals in soils [27]. Thus, application of potassium solubilizing plant growth promoting rhizobacteria as biofertilizer for agriculture improvement can reduce the use of agrochemicals and support ecofriendly crop production.

Siderophore production: Iron is an essential micronutrient for almost all organisms in the biosphere. Despite the fact that iron is the fourth most abundant element on earth, in aerobic soils, iron is not readily assimilated by either bacteria or plants because ferric ion or $\mathrm{Fe}^{+3}$, which is the predominant form in nature, is only sparingly soluble so that the amount of iron available for assimilation by living organisms is extremely low [28]. Microorganisms have evolved specialized mechanisms for the assimilation of iron, including the production of low molecular weight iron-chelating compounds known as siderophores, which transport this element into their cells $[29,30]$. Siderophores are divided into three main families depending on the characteristic functional group, i.e. hydroxamates, catecholates and carboxylates. At present more than 500 different types of siderophores are known, of which 270 have been structurally characterized [31].

Siderophores have been implicated for both direct and indirect enhancement of plant growth by plant growth promoting rhizobacteria. The direct benefits of bacterial siderophores on the growth of plants have been demonstrated by using radiolabeled ferricsiderophores as a sole source of iron showed that plants are able to take up the labeled iron by a large number of plant growth promoting rhizobacteria including Aeromonas, Azadirachta, Azotobacter, Bacillus, Burkholderia, Pseudomonas, Rhizobium, Serratia and Streptomyces sp. [32] and enhanced chlorophyll level compared to un inoculated plants [33].

Phytohormone production: A wide range of microorganisms found in the rhizosphere are able to produce substances that regulate plant growth and development. Plant growth promoting rhizobacteria produce phytohormones such as auxins, cytokinins, gibberellins and Ethylene can affect cell proliferation in the root architecture by overproduction of lateral roots and root hairs with a subsequent increase of nutrient and water uptake [29].

Indole Acetic Acid (IAA): Among plant growth regulators, indole acetic acid (IAA) is the most common natural auxin found in plants and its positive effect on root growth [34]. Up to $80 \%$ of rhizobacteria can synthesize indole acetic acid (IAA) colonized the seed or root surfaces is proposed to act in conjunction with endogenous IAA in plant to stimulate cell proliferation and enhance the host's uptake of minerals and nutrients from the soil [18]. Indole acetic acid affects plant cell division, extension, and differentiation; stimulates seed and tuber germination; increases the rate of xylem and root development; controls processes of vegetative growth; initiates lateral and adventitious root formation; mediates responses to light, gravity and florescence; affects photosynthesis, pigment formation, biosynthesis of various metabolites, and resistance to stressful conditions [35].

Tryptophan is an amino acid commonly found in root exudates, has been identified as main precursor molecule for biosynthesis of IAA in bacteria [36]. The biosynthesis of indole acetic acid by plant growth promoting rhizobacteria involves formation via indole-3pyruvic acid and indole-3-acetic aldehyde, which is the most common mechanism in bacteria like Pseudomonas, Rhizobium, Bradyrhizobium, Agrobacterium, Enterobacter and Klebsiella [37]. Rootgrowth promotion by the free living PGPR e.g., Alkaligenes faecalis, Enterobacter cloacae, Acetobacter dizotrophicous, species of Azospirillum, Pseudomonas and Xanthomonas sp. has been related to low level of IAA secretion. However, microbially produced phytohormones are more effective due to the reason that the threshold between inhibitory and stimulatory levels of chemically produced hormones is low, while microbial hormones are more effective by virtue of their continuous slow release.

Cytokinins and gibberellins: Several plant growth promoting rhizobacteria Azotobacter sp., Rhizobium sp., Pantoea agglomerans, Rhodospirillum rubrum, Pseudomonas fluorescens, Bacillus subtilis and Paenibacillus polymyxa can produce cytokinins or gibberellins or both can produce either cytokinins or gibberellins or both for plant growth promotion [38]. Some strains of phytopathogens can also synthesize cytokinins. However, it appears that plant growth promoting rhizobacteria produce lower cytokinin levels compared to phytopathogens so that the effect of the plant growth promoting rhizobacteria on plant growth is stimulatory while the effect of the cytokinins from pathogens is inhibitory.

Ethylene is a key phytohormone has a wide range of biological activities can affect plant growth and development in a large number of different ways including promoting root initiation, inhibiting root elongation, promoting fruit ripening, promoting lower wilting, stimulating seed germination, promoting leaf abscission, activating the synthesis of other plant hormones [39]. The high concentration of ethylene induces defoliation and other cellular processes that may lead to reduced crop performance [12]. The enzyme 1-aminocyclopropane-1 carboxylic acid (ACC) is a pre-requisite for ethylene production, catalyzed by ACC oxidase. Iqbal MA et al. [40] reported improved nodule number, nodule dry weight, fresh biomass, grain yield, straw yield, and nitrogen content in grains of lentil as a result of lowering of the ethylene production via inoculation with plant growth promoting strains of Pseudomonas sp. containing ACC deaminase along with $R$. leguminosarum. Currently, bacterial strains exhibiting ACC deaminase activity have been identified in a wide range of genera 
such as Acinetobacter, Achromobacter, Agrobacterium, Alcaligenes, Azospirillum, Bacillus, Burkholderia, Enterobacter, Pseudomonas, Ralstonia, Serratia and Rhizobium etc. [38].

In-direct mechanisms: Phytopathogenic microorganisms are a major and chronic threat to sustainable agriculture and ecosystem stability worldwide subverts the soil ecology, disrupt environment, degrade soil fertility and consequently show harmful effects on human health, along with contaminating ground water. Plant growth promoting rhizobacteria is a promising sustainable and environmentally friendly approach to obtain sustainable fertility of the soil and plant growth indirectly. This approach takes inspire a wide range of exploitation of plant growth promoting rhizobacteria led to reducing the need for agrochemicals (fertilizers and pesticides) for improve soil fertility by a variety of mechanisms that via production of antibiotics, siderophores, $\mathrm{HCN}$, hydrolytic enzymes etc $[41,42]$.

Antibiosis: The production of antibiotics is considered to be one of the most powerful and studied biocontrol mechanisms of plant growth promoting rhizobacteria against phytopathogens has become increasingly better understood over the past two decades [37]. A variety of antibiotics have been identified, including compounds such as amphisin, 2,4-diacetylphloroglucinol (DAPG), oomycin A, phenazine, pyoluteorin, pyrrolnitrin, tensin, tropolone, and cyclic lipopeptides produced by pseudomonads [43] and oligomycin A, kanosamine, zwittermicin A, and xanthobaccin produced by Bacillus, Streptomyces, and Stenotrophomonas sp. to prevent the proliferation of plant pathogens (Generally fungi) [44]. One problem with depending too much on antibiotic-producing plant growth promoting rhizobacteria as biocontrol agents is some phytopathogens may develop resistance to specifc antibiotics due to increased use of these strains. To prevent this from happening, some researchers have utilized biocontrol strains that synthesize one or more antibiotics [45]. In soils, antibiotic 2, 4-diacetylphloroglucinol (2, 4- DAPG) producing Pseudomonas sp. was reported for biocontrol of disease in wheat caused by the fungus Gaeumanomyces graminis var. tritici [46]. Bacterization of wheat seeds with $P$. fluorescens strains producing the antibiotic phenazine-1carboxylic acid (PCA) resulted in significant suppression of take-all in about $60 \%$ of field trials [47]. Bacillus amyloliquefaciens is known for lipopeptide and polyketide production for biological control activity and plant growth promotion activity against soil borne pathogens [48]. Apart from the production of antibiotic, some rhizobacteria are also capable of producing volatile compound known as hydrogen cyanide (HCN) for biocontrol of black root rot of tobacco, caused by Thielaviopsis basicola [49]. Lanteigne et al. [50] also reported the production of DAPG and HCN by Pseudomonas contributing to the biological control of bacterial canker of tomato.

Lytic enzymes: Growth enhancement through enzymatic activity is another mechanism used by plant growth promoting rhizobacteria. Plant growth promoting rhizobacterial strains can produce certain enzymes such as chitinases, dehydrogenase, $\beta$-glucanase, lipases, phosphatases, proteases etc. [51,52] exhibit hyperparasitic activity, attacking pathogens by excreting cell wall hydrolases. Through the activity of these enzymes, plant growth promoting rhizobacteria play a very significant role in plant growth promotion particularly to protect them from biotic and abiotic stresses by suppression of pathogenic fungi including Botrytis cinerea, Sclerotium rolfsii, Fusarium oxysporum, Phytophthora sp., Rhizoctonia solani, and Pythium ultimum [53,54].

Numbers of reports have shown the effectiveness of plant growth promoting rhizobacteria as biocontrol agents including Pseudomonas fluorescens CHA0 suppresses black root rot of tobacco caused by the fungus Thielaviopsis basicola [55], Pseudomonas putida against Macrophomina phaseolina in chickpea and Azotobacter chroococcum against Fusarium oxysporum in Sesamum indicum respectively in field condition [9]. In recent years, Pseudomonas fluorescens has been suggested as potential biological control agent due to its ability to colonize rhizosphere and protect plants against a wide range of important agronomic fungal diseases such as black root-rot of tobacco, root-rot of mustard and damping-off of sugar beet in field condition [56-58]. It has been demonstrated that inoculation of plant with arbascular mycorrhiza also improves plant growth. Some strains of Trichoderma have been widely used as biological control agents as well as plant growth promoters [59]. Inoculation with Trichoderma sp. has been the preferred choice for novel biocontrol agents against Aspergillus niger the causal agent of collar rot of peanut [60]. The use of multistrain inoculants are also be a good strategy that enables organisms to successfully survive, maintain themselves in communities. Singh et al. [61] recently showed the synergistic effect of antagonistic fungi Trichoderma with combined application of Pseudomonas and rhizobial strains can protect chickpea from infection by the collar rot pathogen Sclerotium rolfsii.

Siderophore: Iron is an essential growth cofactor for living organisms. For the soil microorganisms, availability of solubilized ferric ion in soils is limited at neutral and alkaline $\mathrm{pH}$. Siderophore producing plant growth promoting rhizobacteria can prevent the proliferation of pathogenic microorganisms by sequestering $\mathrm{Fe}^{3+}$ in the area around the root [62]. These siderophores binds with ferric ion and make siderophore-ferric complex which subsequently binds with ironlimitation-dependent receptors at the bacterial cell surface. The Ferric ion is subsequently released and active in the cytoplasm as ferrous ion.

Many plants can use various bacterial siderophores as iron sources, although the total concentrations are probably too low to contribute substantially to plant iron uptake. Various studies showed isolation of siderophore producing bacteria belonging to the Bradyrhizobium, Pseudomonas, Rhizobium, Serratia and Streptomyces genera from the rhizosphere [63].

Induced systemic resistance (ISR): Induced resistance may be defined as a physiological state of enhanced defensive capacity elicited in response to specific environmental stimuli and consequently the plant's innate defenses are potentiated against subsequent biotic challenges [64]. Biopriming plants with some plant growth promoting rhizobacteria can also provide systemic resistance against a broad spectrum of plant pathogens. Diseases of fungal, bacterial, and viral origin and in some instances even damage caused by insects and nematodes can be reduced after application of plant growth promoting rhizobacteria [65]. Moreover, induced systemic resistance involves jasmonate and ethylene signaling within the plant and these hormones stimulate the host plant's defense responses against a variety of plant pathogens [45]. Many individual bacterial components induce induced systemic resistance such as lipopolysaccharides (LPS), flagella, siderophores, cyclic lipopeptides, 2, 4-diacetylphloroglucinol, homoserine lactones, and volatiles like, acetoin and 2, 3-butanediol [66].

Exo polysaccharides production or biofilm formation: Certain bacteria synthesize a wide spectrum of multifunctional polysaccharides including intracellular polysaccharides, structural polysaccharides, and extracellular polysaccharides. Production of exo polysaccharides is generally important in biofilm formation; root colonization can affect the interaction of microbes with roots appendages. Effective colonization of plant roots by EPS-producing microbes helps to hold 
the free phosphorous from the insoluble one in soils and circulating essential nutrient to the plant for proper growth and development and protecting it from the attack of foreign pathogens. Other innumerable functions performed by EPS producing microbes constitute shielding from desiccation, protection against stress [67], attachment to surfaces plant invasion, and plant defense response in plant-microbe interactions [68]. Plant growth promoting rhizobacterial producing exo polysaccharides are highly important in promoting plant growth due to work as an active signal molecule during beneficial interactions, and provide defense response during infection process [69]. Some plant growth promoting rhizobacterial producing exo polysaccharides can also bind cations, including $\mathrm{Na}^{+}$suggesting a role in mitigation of salinity stress by reducing the content of $\mathrm{Na}^{+}$available for plant uptake [29].

\section{Commercialization of PGPR}

The success and commercialization of plant growth promoting rhizobacterial strains depend on the linkages between the scientific organizations and industries. Numerous work done showed different stages in the process of commercialization include isolation of antagonist strains, screening, fermentation methods, mass production, formulation viability, toxicology, industrial linkages, quality control and field efficacy [70]. Moreover, commercial success of PGPR strains requires economical and viable market demand, consistent and broad spectrum action, safety and stability, longer shelf life, low capital costs and easy availability of career materials.

\section{Plant growth promotory bioformulations}

Bioformulations are best defined as biologically active products containing one or more beneficial microbial strains in an easy to use and economical carrier material. Most bioformulations are meant for field application, it is essential that suitable carrier materials are used to maintain cell viability under adverse environmental conditions. A good quality formulation promotes survival of bacteria maintaining available population sufficient to exude growth promoting effects on plants [71]. Plant growth promoting rhizobacterial bioformulation refers to preparations of microorganism that may be partial or complete substitute for chemical fertilization, pesticides, offer an environmentally sustainable approach to increase crop production and health.

\section{Formulation design}

Formulation is the crucial issue for inoculants containing an effective bacterial strain and can determine the success or failure of a biological agent. The use of inoculant formulations involving carrier materials for the delivery of microbial cells to soil or the rhizosphere is an attractive option. Carrier materials are generally intended to provide a protective niche to microbial inoculants in soil, either physically, via the provision of a protective surface or pore space or nutritionally, via the provision of a specific substrate.

Bioformulation of plant growth promoting rhizobacteria should be composed of a superior carrier material such as high waterholding capacity, high water retention capacity, no heat production from wetting, nearly sterile, chemically uniform, physically uniform, nontoxic in nature, easily biodegradable, nonpolluting, nearly neutral $\mathrm{pH}$ (or easily adjustable $\mathrm{pH}$ ), and supports bacterial growth and survival. Apart from these materials, many other synthetic and inert materials, such as vermiculite, ground rock phosphate, calcium sulfate, polyacrylamide gels, and alginate have also been evaluated [72].
Drying is a part of many procedures for development of formulation of microbial inoculants. Remarkably low percentage of endospore formers was observed that survived after drying [54]. One factor which can have a detrimental effect on dried microorganisms over the long term is humidity in the environment; increasing moisture content of the dried sample compromises viability. Storage under vacuum or in an inert atmosphere can prevent this but is costly and unwieldy. The use of each type of inoculant depends upon market availability, choice of farmers, cost, and the need of a particular crop under specific environmental conditions [73].

\section{Future Research and Development Strategies for Sustainable Technology}

The need of today's world is high output yield and enhanced production of the crop as well as fertility of soil to get in an ecofriendly manner. Hence, the research has to be focused on the new concept of rhizoengineering based on favorably partitioning of the exotic biomolecules, which create a unique setting for the interaction between plant and microbes [74]. Future research in rhizosphere biology will rely on the development of molecular and biotechnological approaches to increase our knowledge of rhizosphere biology and to achieve an integrated management of soil microbial populations. Fresh alternatives should be explored for the use of bioinoculants for other high value crops such as vegetables, fruits, and flowers. The application of multi strain bacterial consortium over single inoculation could be an effective approach for reducing the harmful impact of stress on plant growth. The addition of ice-nucleating plant growth promoting rhizobacteria could be an effective technology for enhancing plant growth at low temperature [53].

Research on nitrogen fixation and phosphate solubilization by plant growth promoting rhizobacteria is progress on but little research can be done on potassium solubilization which is third major essential macronutrient for plant growth. This will not only increase the field of the inoculants but also create confidence among the farmers for their use. In addition, future marketing of bioinoculant products and release of these transgenics into the environment as eco-friendly alternations to agrochemicals will depend on the generation of biosafety data required for the registration of plant growth promoting rhizobacterial agents. A part from that future research in optimizing growth condition and increased self life of PGPR products, not phytotoxic to crop plants, tolerate adverse environmental condition, higher yield and cost effective PGPR products for use of agricultural farmer will be also helpful.

\section{References}

1. Youssef MMA, Eissa MFM (2014) Biofertilizers and their role in management of plant parasitic nematodes. E J Biotechnol Pharm Res 5: 1-6.

2. Joshi KK, Kumar V, Dubey RC, Maheshwari DK (2006) Effect of chemical fertilizer adaptive variants, Pseudomonas aeruginosa GRC2 and Azotobacter chroococcum AC1 on Macrophomena phaseolina causing charcoal rot of Brassica juncea. Korean J Environ Agric 25: 228-235.

3. Hiltner L (1904) liber neuere Erfahrungen und unter besondere Berucksichtingung der Grundunging und Brache. Arb Dtsch Landw Ges 98: 59-78.

4. Akhtar N, Qureshi MA, Iqbal A, Ahmad MJ, Khan KH (2012) Influence of Azotobacter and IAA on symbiotic performance of Rhizobium and yield parameters of lentil. J Agric Res 50: 361-372.

5. Kloepper JW, Leong J, Teintze M, Scroth MN (1980) Enhancement of plant growth by siderophores produced by plant growth promoting rhizobacteria. Nature (London) 286: 885-886.

6. Ahemad M, Khan MS (2009) Effect of insecticide-tolerant and plant growth 
Citation: Gupta G, Parihar SS, Ahirwar NK, Snehi SK, Singh V (2015) Plant Growth Promoting Rhizobacteria (PGPR): Current and Future Prospects for Development of Sustainable Agriculture. J Microb Biochem Technol 7: 096-102. doi:10.4172/1948-5948.1000188

promoting Mesorhizobium on the performance of chickpea grown in insecticide stressed alluvial soils. J Crop Sci Biotechnol 12: 213-222.

7. Sivasakhti S, Usharani G, Saranraj $P(2014)$ Biocontrol potentiality of plant growth promoting bacteria (PGPR)- Pseudomonas fluorescence and Bacillus subtilis: A review. African Journal of Agricultural Research 9: 1265-1277.

8. Sagar S, Dwivedi A, Yadav S, Tripathi M, Kaistha SD (2012) Hexavalent chromium reduction and plant growth promotion by Staphylococcusarlettae strain Cr11. Chemosphere 86: 847-852.

9. Maheshwari DK, Dubey RC, Aeron A, Kumar B, Kumar S, et al (2012) Integrated approach for disease management and growth enhancement of Sesamum indicum L. utilizing Azotobacter chroococcum TRA2 and chemical fertilizer. World J Microbiol Biotechnol 28: 3015-3024.

10. Viveros OM, Jorquera MA, Crowley DE, Gajardo G, Mora ML (2010) Mechanisms and practical considerations involved in plant growth promotion by rhizobacteria. J Soil Sci Plant Nutr 10: 293-319.

11. Ahemad M, Kibret M (2014) Mechanisms and applications of plant growth promoting rhizobacteria: Current perspective. Journal of King Saud University - Science 26: 1-20.

12. Bhattacharyya PN, Jha DK (2012) Plant growth-promoting rhizobacteria (PGPR): emergence in agriculture. World J Microbiol Biotechnol 28: 13271350

13. Kloepper JW, Schroth MN (1981) Relationship of in vitro antibiosis of plan growth promoting rhizobacteria to plant growth and the displacement of root microflora. Phytopathol 71: 1020-1024.

14. Bhardwaj D, Ansari MW, Sahoo RK, Tuteja N (2014) Biofertilizers function as key player in sustainable agriculture by improving soil fertility, plant tolerance and crop productivity. Microb Cell Fact 13: 66.

15. Arora NK, Tewari S, Singh S, Lal N, Maheshwari DK (2012) PGPR for protection of plant health under saline conditions. In: Maheshwari DK (ed.) Bacteria in agrobiology: Stress management, pp. 239-258.

16. Gaby JC, Buckley DH (2012) A comprehensive evaluation of PCR primers to amplify the nifH gene of nitrogenase. PLoS One 7: e42149.

17. Zahran HH (2001) Rhizobia from wild legumes: diversity, taxonomy, ecology, nitrogen fixation and biotechnology. J Biotechnol 91: 143-153.

18. Vessey JK (2003) Plant growth promoting rhizobacteria as biofertilizers. Plant Soil 255: 571-586.

19. Reed SC, Cleveland CC, Townsend AR (2011) Functional ecology of free-living nitrogen fixation: a contemporary perspective. Annu Rev Ecol Evol Syst 42: 489-512

20. Khan MS, Zaidi A, Ahemad M, Oves M, Wani PA (2010) Plant growth promotion by phosphate solubilizing fungi - current perspective. Arch Agron Soil Sci 56: 73-98

21. Pandey P, Maheshwari DK (2007) Two sp. microbial consortium for growth promotion of Cajanus Cajan. Curr Sci 92: 1137-1142

22. Sharma SB, Sayyed RZ, Trivedi MH, Gobi TA (2013) Phosphate solubilizing microbes: sustainable approach for managing phosphorus deficiency in agricultural soils. Springerplus 2: 587 .

23. Zaidi A, Khan MS, Ahemad M, Oves M (2009) Plant growth promotion by phosphate solubilizing bacteria. Acta Microbiol Immunol Hung 56: 263-284.

24. Parmar P, Sindhu SS (2013) Potassium Solubilization by Rhizosphere Bacteria: Influence of Nutritional and Environmental Conditions. J Microbiol Res 3: 25-31.

25. Kumar P, Dubey RC (2012) Plant Growth Promoting Rhizobacteria for Biocontrol of Phytopathogens and Yield Enhancement of Phaseolus vulgaris. $J$ Curr Pers Appl Microbiol 1: 6-38.

26. Han HS, Lee KD (2006) Effect of co-inoculation with phosphate and potassium solubilizing bacteria on mineral uptake and growth of pepper and cucumber Plant Soil Environ 52: 130-136.

27. Liu D, Lian B, Dong H (2012) Isolation of Paenibacillus sp. and assessment of its potential for enhancing mineral weathering. Geomicrobiology J 29: 413-421.

28. Ma JF (2005) Plant root responses to three abundant soil minerals: silicon, aluminum and iron. Crit Rev Plant Science 24: 267-281

29. Arora NK, Tewari S, Singh R (2013) Multifaceted Plant-Associated Microbes and Their Mechanisms Diminish the Concept of Direct and Indirect PGPRs.
In: Arora NK (ed.) Plant Microbe Symbiosis: Fundamentals and Advances. Springer, 411-449

30. Schwyn B, Neilands JB (1987) Universal chemical assay for the detection and determination of siderophores. Anal Biochem 160: 47-56.

31. Cornelis P (2010) Iron uptake and metabolism in pseudomonads. App Microbiol Biotechnol 86: 1637-1645.

32. Sujatha N, Ammani K (2013) Siderophore production by the isolates of fluorescent Pseudomonads. Int J Cur Res Rev 5: 1-7

33. Sharma A, Johri BN, Sharma AK and Glick BR (2003) Plant growth-promoting bacterium Pseudomonas sp. strain GRP3 infuences iron acquisition in mung bean (Vigna radiata L. Wilzeck). Soil Biol Biochem 35: 887-894

34. Miransari M, Smith DL (2014) Plant hormones and seed germination. Environmental and Experimental Botany 99: 110- 121

35. Spaepen S, Vanderleyden J (2011) Auxin and plant-microbe interactions. Cold Spring Harb Perspect Biol 3: a001438.

36. Etesami HA, Alikhani HA, Akbari A (2009) Evaluation of plant growth hormones production (IAA) ability by Iranian soils rhizobial strains and effects of superior strains application on wheat growth indexes. World Appl Sci J 6: 1576-1584.

37. Shilev S (2013) Soil Rhizobacteria Regulating the Uptake of Nutrients and Undesirable Elements by Plants. In: Arora NK (ed.) Plant Microbe Symbiosis: Fundamentals and Advances. Springer, India, 147-50

38. Kang BG, Kim WT, Yun HS, Chang SC (2010) Use of plant growth-promoting rhizobacteria to control stress responses of plant roots. Plant Biotechnol Rep 4: 179-183.

39. Glick BR, Todorovic B, Czarny J, Cheng Z, Duan J, et al. (2007) Promotion of plant growth by bacterial ACC deaminase. Crit Rev Plant Sci 26: 227-242.

40. Iqbal MA, Khalid M, Shahzad SM, Ahmad M, Soleman N, et al. (2012) Integrated use of Rhizobium leguminosarum, plant growth promoting rhizobacteria and enriched compost for improving growth, nodulation and yield of lentil (Lens culinaris Medik). Chilean J Agric Res 72: 104-110.

41. Tariq M, Hameed S, Yasmeen T, Zahid M, et al. (2014) Molecular characterization and identification of plant growth promoting endophytic bacteria isolated from the root nodules of pea (Pisum sativum L.) World $J$ Microbiol Biotechnol 30: 719-725.

42. Lugtenberg B, Kamilova F (2009) Plant-growth-promoting rhizobacteria. Annu Rev Microbiol 63: 541-556.

43. Loper JE, Gross H (2007) Genomic analysis of antifungal metabolite production by Pseudomonas fluorescens Pf-5. Eur J Plant Pathol 119: 265-278.

44. Compant S, Reiter B, Sessitsch A, Nowak J, Clément C, et al. (2005) Endophytic colonization of Vitis vinifera L. by plant growth-promoting bacterium Burkholderia sp. strain 45. PsJN. Appl Environ Microbiol 71: 1685-1693.

45. Glick BR (2012) Plant growth-promoting bacteria: mechanisms and applications Scientifica (Cairo) 2012: 963401

46. de Souza JT, Weller DM, Raaijmakers JM (2003) Frequency, diversity and activity of 2, 4-diacetylphloroglucinol producing fluorescent Pseudomonas spp. in Dutch take-all decline soils. Phytopathol 93: 54-63.

47. Weller DM (2007) Pseudomonas biocontrol agents of soilborne pathogens: looking back over 30 years. Phytopathology 97: 250-256

48. Ongena M, Jacques $P$ (2008) Bacillus lipopeptides: versatile weapons for plan disease biocontrol. Trends Microbiol 16: 115-125.

49. Sacherer P, Défago G, Haas D (1994) Extracellular protease and phospholipase $\mathrm{C}$ are controlled by the global regulatory gene gacA in the biocontrol strain Pseudomonas fluorescens CHA0. FEMS Microbiol Lett 116: 155-160.

50. Lanteigne C, Gadkar VJ, Wallon T, Novinscak A, Filion M (2012) Production of DAPG and HCN by Pseudomonas sp. LBUM300 contributes to the biological control of bacterial canker of tomato. Phytopathology 102: 967-973.

51. Joshi M, Shrivastava R, Sharma AK, Prakash A (2012) Screening of resistant verities and antagonistic Fusarium oxysporum for biocontrol of Fusarium Wilt of Chilli. Plant Pathol Microbiol 3: 134.

52. Hayat R, Ali S, Amara U. Khalid R, Ahmed I (2010) Soil beneficial bacteria and their role in plant growth promotion: A review. Ann Microbiol 60: 579-598.

53. Nadeem SM, Naveed M, Zahir ZA, Asghar HN (2013) Plant-Microbe Interactions 
Citation: Gupta G, Parihar SS, Ahirwar NK, Snehi SK, Singh V (2015) Plant Growth Promoting Rhizobacteria (PGPR): Current and Future Prospects for Development of Sustainable Agriculture. J Microb Biochem Technol 7: 096-102. doi:10.4172/1948-5948.1000188

for Sustainable Agriculture: Fundamentals and Recent Advances. In: Arora NK (ed.) Plant Microbe Symbiosis: Fundamentals and Advances. Springer, India pp. 51-103.

54. Upadyay SK, Maurya SK, Singh DP (2012) Salinity tolerance in free living plant growth promoting Rhizobacteria. Ind J Sci Res 3: 73-78.

55. Voisard C, Keel C, Haas D, Dèfago G (1989) Cyanide production by Pseudomonas fluorescens helps suppress black root rot of tobacco under gnotobiotic conditions. EMBO J 8: 351-358.

56. Arora NK, Khare E, Verma A, Sahu RK (2008) In vivo control of Macrophomina phaseolina by a chitinase and $\beta-1,3$ glucanse producing pseudomonad NDN1. Symbiosis 46: 129-135

57. Fenton AM, Stephens PM, Crowley J, O'Callaghan M, O'Gara F (1992) Exploitation of gene(s) involved in 2, 4- diacetylphloroglucinol biosynthesis to confer a new biocontrol capability to a Pseudomonas strain. Applied and Environmental Microbiology 58: 3873-3878.

58. Kumar NR, Arasu VT, Gunasekaran P (2002) Genotyping of antifungal compounds producing plant growth-promoting rhizobacteria, Pseudomonas fluorescens. Current Science 82: 1465-1466.

59. Rabeendran N, Moot DJ, Jones EE, Stewart A (2000) Inconsistent growth promotion of cabbage and lettuce from Trichoderma isolates. New Zealand Journal of Plant Protection 53: 143-146.

60. Gajera HP, Vakharia DN (2012) Production of Lytic Enzymes by Trichoderma Isolates during in vitro Antagonism with Aspergillus Niger, The Causal Agent of Collar ROT of Peanut. Braz J Microbiol 43: 43-52.

61. Singh A, Sarma BK, Upadhyay RS, Singh HB (2013) Compatible rhizosphere microbes mediated alleviation of biotic stress in chickpea through enhanced antioxidant and phenylpropanoid activities. Microbiological Research 168: 33- 40.

62. Mehnaz S (2013) Secondary Metabolites of Pseudomonas aurantiaca and Their Role in Plant Growth Promotion. In: Arora NK (ed.) Plant Microbe Symbiosis: Fundamentals and Advances. Springer, India, pp. 373-394.

63. Kuffner M, Puschenreiter M, Wieshammer G, Gorfer M, Sessitsch A (2008) Rhizosphere bacteria affect growth and metal uptake of heavy metal accumulating willows. Plant Soil 304: 35- 44

64. Avis TJ, Gravel V, Antoun H, Tweddell RJ (2008) Multifaceted beneficial effects of rhizosphere microorganisms on plant health and productivity. Soil Biol Biochem 40: 1733-1740.
65. Naznin HA, Kimura M, Miyazawa M, Hyakumachi M (2012) Analysis of volatile organic compounds emitted by plant growth promoting fungus phoma sp. GS83 for growth promotion effects on tobacco. Microbe Environ 28: 42-49.

66. Doornbos RF, van Loon LC, Peter AHM, Bakker A (2012) Impact of root exudates and plant defense signaling on bacterial communities in the rhizosphere. Rev Sustain Dev 32: 227-243.

67. Qurashi AW, Sabri AN (2012) Bacterial exopolysaccharide and biofilm formation stimulate chickpea growth and soil aggregation under salt stress. Braz J Microbiol 43: 1183-1191.

68. Tewari S, Arora NK (2014) Multifunctional exopolysaccharides from Pseudomonas aeruginosa PF23 involved in plant growth stimulation, biocontro and stress amelioration in sunflower under saline conditions. Current Microbio 69: 484-494.

69. Parada M, Vinardell J, Ollero F, Hidalgo A, Gutiérrez R, et al. (2006) Sinorhizobium fredii $\mathrm{HH} 103$ mutants affected in capsular polysaccharide (KPS) are impaired for nodulation with soybean and Cajanus cajan. Mol Plant Microbe Interact 19: 43-52.

70. Nandakumar R, Babu S, Viswanathan R, Sheela J, Raguchander T, et al.( 2001) A new bio-formulation containing plant growth promoting rhizobacterial mixture for the management of sheath blight and enhanced grain yield in rice. Biocontrol 46: 493-510.

71. Singh S, Gupta G, Khare E, Behal KK, Arora NK (2014) Effect of enrichment material on the shelf life and field efficiency of bioformulation of Rhizobium $\mathrm{sp}$. and P-solubilizing Pseudomonas fluorescens. Science Research Reporter 4 44-50.

72. Domenech J, Reddy MS, Kloepper JW, Ramos B, Gutierrez-Mañero J (2006) Combined application of the biological product LS213 with Bacillus, Pseudomonas or Chryseobacterium for growth promotion and biological control of soil-borne diseases in pepper and tomato. Bio Control 51: 245-258.

73. Arora NK, Khare E, Maheshwari DK (2010) Plant growth promoting rhizobacteria: constraints in bioformulation, commercialization, and future strategies. In: Maheshwari DK (ed.) Plant growth and health promoting bacteria. Springer, $18: 97-116$.

74. Tewari S, Arora NK (2013) Transactions among Microorganisms and Plant in the Composite Rhizosphere. In: Arora NK (ed.) Plant Microbe Symbiosis: Fundamentals and Advances. Springer, pp. 1-50. 